\title{
Discussion on Multi-generational Sharing Mode of Urban Community Resources based on the Goal of Helping the Aged
}

\author{
Xiang Wei \\ Zhejiang International Studies University, School of ARTS, Zhejiang, Hangzhou, 310000
}

Keywords: Community; Spatial resources; Information resources; Composition; Sharing

\begin{abstract}
In a recycling-based society, mutual benefit has become a new concept, which provides new ideas for urban community home care. Community public space and community virtual space are two places for behavioral activities in the community. This paper aims to explore the possibility of excavating new ways of home care by analyzing their multi-generational sharing model in the context of helping the aged.
\end{abstract}

\section{Introduction}

With the development of economy, the social form has gradually changed from industrial to cyclical. The rational allocation of social resources and the mutual benefit sharing have become new ideas that have permeated into daily life. At the community level, there is also discussions of community forms characterized by mutual benefit sharing. How to realize the intergenerational sharing of urban community resources under the goal of helping the aged, and to meet the different needs of different generations in the society has become a concern of the whole.

\section{Community resources are symbiosis with network form}

Sharing is a phenomenon associated with a recycling-based society and is an act that occurs in a particular space. In behavioral geography, the geographical boundary of people's activities is called behavioral space. It includes both the spatial scope of human direct activity and indirect activities. There are differences in the spatial extents of different types. The community is not an entity concept, it is more like a "network" collection. Members of the community are based on geographically connected, but there are also dependencies. Therefore, the discussion of sharing community resource should not only stay at the level of physical space, but should be regarded as a symbiotic network form.

\subsection{Community public space resources}

The behavior generated in the community public space is mostly based on daily needs, mostly basic needs, such as commuting/studying, communication, leisure and shopping, etc. These activities have certain directivity of purpose, and they are also places and paths that people experience in daily life, work and study, which is classified as direct activity space in the concept of behavior space. Given the absence of space and the lack of space to facilitate the interactive communication between members of different ages, the interaction among members is bound to be limited, thus it is difficult to maintain the vitality of the community. Therefore, the construction of community public space is an important aspect to discuss the multi-generational sharing of community resources.

\subsection{Community information resources}

Indirect activity space refers to the space that people know through indirect communication, including the space that they know through personal contact such as mail and phone, and also the space that they get through media such as newspaper, magazine, radio, television and computer. It is closely related to communication and is a virtual space different from community public space.

For most community researchers, the concept of community is mostly related to a particular 
geographic scope, thus physical space is studied in the research. However, with the modernization process, the study of community morphology based on regional relationship is no longer the whole research of a community. Community is no longer a fixed physical space, but a network relationship.

In my survey, the most frequent interaction points in the community BBS network focus on helping each other solve problems in life and sharing various local life information. From this point, it can be seen that community members' interaction in virtual space has a strong sense of mutual help. Community members are both helping and receiving persons. While using this kind of social mutual aid resources, each member has realized mutual benefit and improved each other's quality of life.

\section{Sharing mode targeted at helping the old}

\subsection{Concept}

The existing Internet + community home care system is dominated by the government, which coordinates different departments such as civil affairs, finance, health and social security, and purchases the information network guaranteeing service operation from the third party. The government adopts the management mode of classification and classification, and allocates the content of elderly care services such as life care, medical care, housekeeping service and spiritual consolation to different departments such as civil affairs, health and industry and commerce. It is precisely this segmented management system that causes the problem of insufficient interaction and communication between government agencies, third-party organizations and various subjects in the family, which limits the immediacy of services and makes it difficult to meet the needs of homebased care.

However, in recent years, more and more BBS networks have become an important community medium. For example, the emergence of community WeChat group makes it a kind of social resource that community members depend on and benefit each other. Government provides and maintains community infrastructure; Community members assume the role of providing information resources; Private and non-profit organizations provide technical support. When we realize that old-age care is a process that everyone is bound to go through, and that Shared Concepts and Shared Communities are a major trend of social development, we can improve their sense of participation in the community, activate idle information resources in the community, meet the needs of multi-age residents, and thus provide reliable help for home-based care.

\subsection{Constitute}

The three - dimensional features of the Shared Mode can be unpacked into three layers: physical, virtual and support. The physical level corresponds to the place where the direct activities of the community members take place in the community life. For example, commuting, chatting, playing chess, nursing, shopping, etc., generally take place in the public space such as the passageway, activity center, green space and supermarket in the community. Under the premise of multigeneration sharing, the construction of the place where the activities take place should aim at attracting the gathering of different generations and promoting the interaction between generations.

Indirect activities generated by community members in community life, such as information exchange and organization of residents' spontaneous activities, need not only the actual space to be used as the venue for development, but also human resources and information provided jointly by community members. Through the community social network to develop mutual support services, members provide help to each other, to supplement the resources of the community. So we interpret these as sharing patterns $=$ space + resources + services. 


\section{Shared mode}

\section{1 multi-generational sharing of age-appropriate community space}

According to the degree of aging in China's society and the use time of the elderly members in the community for public space, the multi-generation sharing construction of community public space should be inclusive and slightly inclined to the elderly population. At the same time, the construction of public space shared by different generations of people is not only suitable for a single age group, but also meets the needs of different generations. For example, rides for younger members, sports venues for middle-aged members and rest areas for older members.

\subsection{Multi-generational sharing of information in virtual space}

Software and hardware such as computers and communication equipment are the carriers of such indirect activities. Along with the emergence of new media such as the Internet, unlike the old people who mainly obtained information from traditional media such as newspapers, radio, television, and telephone, the elderly population gradually joined the Internet use group, so the use of virtual space information sharing to help Old goals have become possible.

However, compared with other people, the cognitive ability of the elderly and the ability to accept new things are decreasing. In order to enable them to successfully master the use of the network, participate in information sharing and dissemination within the community and achieve mutual benefit and mutual assistance with other community members, the community virtual social network construction proposal under the premise of intergenerational sharing:

Reduce the strangeness of the elderly to the network. The strangeness and fear of the Internet is the main reason that hinders the elderly from accessing the online social platform. In order to eliminate this obstacle, community service can play the necessary role in addition to the help of family members. The community activity center itself is a place for community members to communicate. In the place, the network provides services for the elderly, which can not only get the opportunity to communicate with others in real life, but also learn how to obtain information in the virtual space.

Develop a page which is suitable for the elderly to browse. When designing pages for all members of the community, try to consider about their physiological characteristics. For example, the size of the font; the color contrast with high recognition; the page layout that conforms to the conventional cognitive habits.

\section{Conclusion}

Guided by the theory of behavioral geography, this paper extends the concept of a community as a physical space to the concept of "network" in the community, and on this basis, explores the intergenerational sharing of community information resources in community resources except public space. It is expected to provide a new perspective for community sharing. When constructing and maintaining a community space environment, it can fully consider its role in the communication of different intergenerational members in the community. Communicating community members as a criterion for community construction and mining communities the mutual help of members.

Although the discussion is still frame-based and requires more detailed research to support, I hope this article can become a multi-generational sharing of community resources, providing useful support for home-based care.

\section{Acknowledgments}

Supported by Civil Policy Theoretical Research Project of Zhejiang Province Project Number: ZMZC201868 


\section{References}

[1] [United States] Reginald Golech / [Australia] Robert Stinson Geography of Space Behavior [M] Chai Yanwei Cao Xiaoyu Long Yi Translated Commercial Press 2013.12

[2] Gui Yong Huang Ronggui. Urban Community: Community or “Unrelated Neighborhoods” [J] Journal of Central China Normal University (Humanities and Social Sciences) 2006.11

[3] Xie Jing Community: The Composition of Communication [J] Journal of Suzhou University (Philosophy and Social Sciences Edition) 2015.05

[4] Liu Wei, Zuo Meiyun, Liu Mancheng, "Empirical Analysis of the Continuous Use of Internet Applications for the Elderly Based on Expectation Confirmation Theory” [J] Management Review 2012.05

[5] Chen Xueli "On the Internet and the continued socialization of the elderly" [J] Press 2015.09 